\title{
LFP oscillations provide a time reference for excess spike synchrony among VI neurons
} Junji Ito*1, Pedro Maldonado ${ }^{2}$ and Sonja Grün ${ }^{1}$

Address: ${ }^{1}$ Theoretical Neuroscience Group, RIKEN Brain Science Institute, 2-1 Hirosawa, Wako, Saitama 351-0198, Japan and ${ }^{2}$ CENI and Programa de Fisiologia y Biofisica, ICBM, Facultad de Medicina, Universidad de Chile, Casilla 70005, Santiago, Chile

Email: Junji Ito* - j-ito@brain.riken.jp

* Corresponding author

from Eighteenth Annual Computational Neuroscience Meeting: CNS*2009

Berlin, Germany. 18-23 July 2009

Published: 13 July 2009

BMC Neuroscience 2009, I0(Suppl I):P267 doi:I0.I I86/I47|-2202-I0-SI-P267

This abstract is available from: http://www.biomedcentral.com//47I-2202/I0/SI/P267

(c) 2009 Ito et al; licensee BioMed Central Ltd.

When inspecting visual scenes, primates perform on average four saccades per second, implying that the processing of image components may be accomplished in less than $200 \mathrm{~ms}$. Individual neurons thereby contribute only with a few spikes for these complex computations, suggesting that information is encoded not only in the firing rate but also in the timing of spikes. Recently, local field potential (LFP) oscillations have been suggested to modulate the timing of single spikes and thus act as a mechanism realizing the temporal coding of neural information. We hypothesized that such mechanism should be apparent in the neuronal activity of V1 during natural visual behavior. Therefore we measured simultaneously neuronal activities and eye movements while monkeys freely view images of natural scenes [1]. In a series of analyses on the recordings in this experiment, we have revealed important properties of the neural activity in the primary visual cortex during free viewing, summarized as follows: (1) the neuronal firing rate starts to increase about $50 \mathrm{~ms}$ after fixation-onset, reaches a peak value at about $70 \mathrm{~ms}$ and then decays slowly [1] (Figure 1a); (2) the LFP shows oscillatory activity in the beta-frequency band during the fixation periods, and these oscillations are locked to the onset of saccades [2] (Figure 1b); (3) the timing of spikes is modulated by these oscillations, i.e. spikes prefer a specific phase of the LFP oscillation (phase locking) [2]; (4) the first visually evoked spikes occurring about $70 \mathrm{~ms}$ after fixation-onset show a much stronger phase locking than all other spikes [3], and (5) spike synchrony across neurons occurs in excess as revealed by the Unitary Event

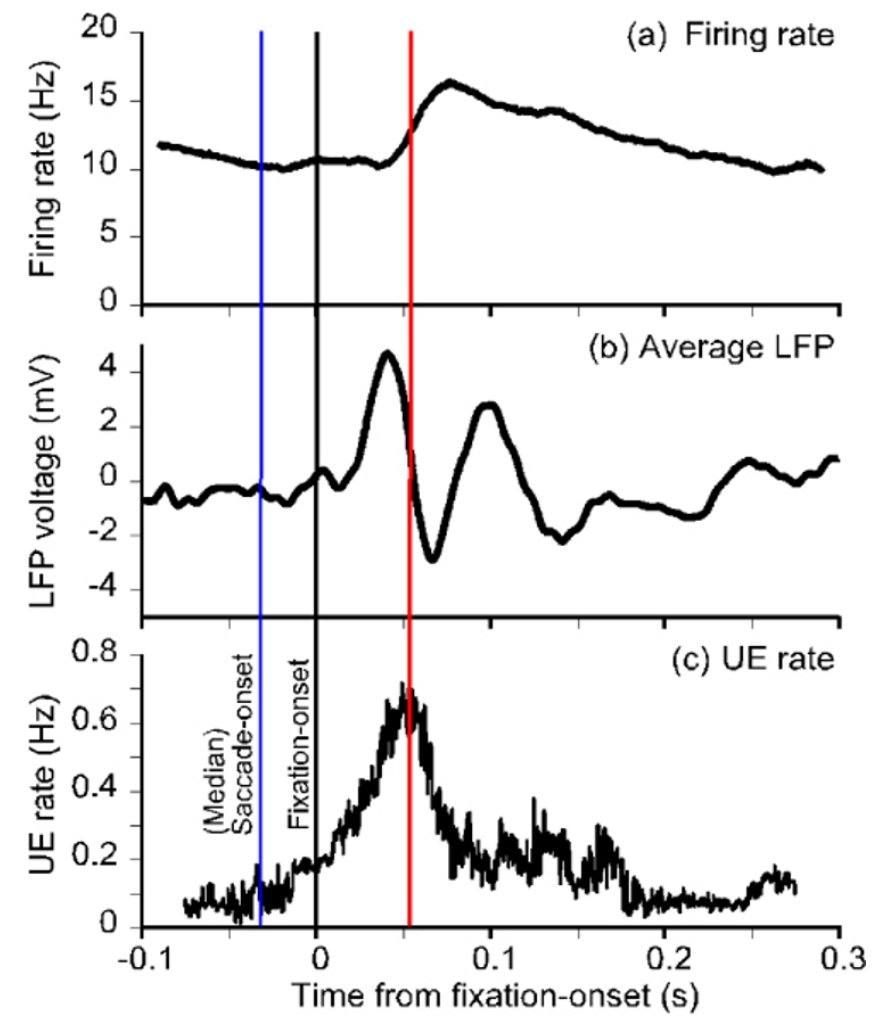

Figure I

Neural activities in VI of free viewing monkey. The blue and red lines indicate the timing of the (median) onset of saccades and the steepest negative slope of LFP, respectively. (a) Mean firing rate of neurons, (b) average LFP, (c) UE rate, all triggered on fixation onset. 
(UE) analysis [4] about $50 \mathrm{~ms}$ after fixation onset and precedes the peak of the firing rates [1].

Based on these findings, we hypothesized that the firing threshold of neurons is effectively modulated in an oscillatory manner due to LFP oscillations. This model predicts that spike synchrony precedes the peak firing rates of the individual neurons, since peak firing rate tends to occur around the trough of the oscillation while the onset of the rate increase (first spikes) should concentrate at the previous, negative slope of the oscillation. Here we show that these predictions hold and that the peak occurrence of UEs indeed occurs at the steepest negative slope of the LFP (Figure 1c, red line). Our observations provide strong support for the interpretation that the beta-band LFP oscillation triggered at saccade-onset reflects an intrinsic, presumably top down, reference signal that enables early visually evoked spikes to precisely lock to this signal. This framework also provides a mechanism to accurately time the spikes of populations of neurons, thereby allowing further processing of visual information via spike synchronization.

\section{References}

I. Maldonado P, Babul C, Singer W, Rodriguez E, Berger D, Grün S: Synchronization of neuronal responses in primary visual cortex of monkeys viewing natural images. J Neurophysiol 2008, 100:1523-1532.

2. Ito J, Maldonado P, Grün S: First spikes in VI are phase locked to saccade-related LFP Oscillations. Frontiers in Computational Neuroscience. Conference Abstract: Bernstein Symposium 2008. doi: 10.3389/conf.neuro. 10.2008.01.066

3. Ito J, Maldonado P, Grün S: Saccade-related LFP oscillations provide a reference frame for spike timing. Program No. 5 I 4. I I. In 2008 Neuroscience Meeting Planner Washington, DC: Society for Neuroscience; 2008. Online.

4. Grün S, Diesmann M, Aertsen A: 'Unitary Events' in multiple single-neuron activity. II. Non-Stationary data. Neural Computation 2002, I4(I):8I-119.
Publish with Biomed Central and every scientist can read your work free of charge

"BioMed Central will be the most significant development for disseminating the results of biomedical research in our lifetime. "

Sir Paul Nurse, Cancer Research UK

Your research papers will be:

- available free of charge to the entire biomedical community

- peer reviewed and published immediately upon acceptance

- cited in PubMed and archived on PubMed Central

- yours - you keep the copyright

Submit your manuscript here:

http://www.biomedcentral.com/info/publishing_adv.asp 